\title{
O ESTADO DE SÃO PAULO COMO UM ATOR INTERNACIONAL
}

\author{
Karina L. Pasquariello Mariano
}

\begin{abstract}
Resumo: Discussão da influência do cenário internacional sobre as decisões dos governos subnacionais e sua ascensão como novos atores neste contexto. As informações apresentadas neste artigo resultaram da pesquisa "Gestão Pública Estratégica de Governos Subnacionais Frente aos Processos de Inserção Internacional e Integração Latino-Americana", que está sendo realizada pela Fundap, PUC-SP e Cedec, e analisam de que modo um governo subnacional reage aos efeitos e à nova realidade internacional, utilizando-se o caso de São Paulo. Palavras-chave: integração regional; governos subnacionais; organismos internacionais.
\end{abstract}

Abstract: A discussion of how the international scene affects the decisions of sub-national governments, and of their ascension as new actors within this context. The information presented in this article was extracted from a research project entitled "Strategic Public Strategies of Sub-national Governments Within the Context of the Processes of Latin American Global Insertion and Integration," currently being conducted by Fundap, (Foundation for Public Administration), PUC-SP (Catholic University of São Paulo) and Cedec. This article examines how sub-national governments react to changing realities at the international level, using the government of the State of São Paulo as a case in point.

Key words: regional integration; sub-national governments; international organizations.

$\mathrm{N}$

o final dos anos 50, Ernest B. Haas elaborou um modelo teórico para analisar o processo de integração na Europa. Seu estudo estava inserido numa perspectiva neofuncional, mas se tornou referência para todas as demais correntes das relações internacionais que pensaram ou pensam o fenômeno do regionalismo.

O conceito fundamental no modelo de Haas é a noção de spillover. ${ }^{1}$ Tendo como ponto de partida a iniciativa burocrático-estatal, o processo iria se "esparramando" (spillover) para a sociedade, criando uma dinâmica de reações, demandas e respostas. A idéia contida nesse conceito é que a integração, ao se aprofundar, mobiliza grupos de interesse existentes na sociedade contra ou a favor do processo. A sociedade não se limita apenas a respeitar os acordos feitos entre os governos, buscando formas de melhor intervir e participar das negociações. Esse interesse dinamiza o processo de integração, tornando-o menos dependente da vontade política dos governos.

Sem entrar na discussão sobre a validade ou as críticas feitas a esse conceito, tal como foi formulado, deve-se considerar que sua idéia central ainda permanece válida: a integração regional, quando bem-sucedida, tende a criar interesse e envolvimento crescentes na sociedade, acarretando a participação de instâncias governamentais e atores que inicialmente ficaram marginalizados.

Conforme as decisões são tomadas e suas conseqüências tornam-se mais evidentes, a integração é paulatinamente incorporada na vida doméstica das nações envolvidas, aproximando sua temática do cotidiano do cidadão comum. Em contrapartida, o maior envolvimento da sociedade influencia a estrutura institucional do processo de integração, pressionando-a para assimilar e se adequar às mudanças e às novas demandas que surgem.

É nesse contexto que os Estados assumem grande importância para o desenvolvimento e legitimação da integração. Entende-se que, para o avanço de uma experiência de integração regional, é importante haver um maior envolvimento dos governos subnacionais nas negociações e na formulação das decisões.

Esta é a questão central da pesquisa "Gestão Pública Estratégica de Governos Subnacionais Frente aos Processos de Inserção Internacional e Integração Latino-Americana", que está sendo realizado pela Fundap (Fundação do Desenvolvimento Administrativo), PUC/SP (Pontifícia Universidade Católica) e Cedec (Centro de Estudos de 
Cultura Contemporânea). Esta pesquisa procura compreender o modo como um governo subnacional reage diante dos efeitos e da nova realidade internacional, analisando o caso do Estado de São Paulo. É reconhecido que o Mercosul e outros organismos internacionais têm impactos sobre essa instância governamental, influenciando de algum modo sua agenda interna e sua estrutura burocrática.

"No cenário internacional recente - marcado pelas tendências de globalização e de integração regional, assim como de democratização da gestão governamental -, é fato que os governos subnacionais passaram a ter maior relevância, inserindo-se como atores também no campo das relações internacionais, haja vista as experiências desses governos no processo de integração regional da União Européia e da América Latina" (Fundap/Cedec/PUC, 2000).

Essa ampliação na atuação dos governos subnacionais ocorre de diferentes modos (exercendo funções de coordenação, articulação, negociação, mobilização e indução dos agentes envolvidos no processo de integração regional) e com intensidade variável. Os Estados do sul do País, devido à proximidade geográfica, sofrem de forma mais intensa os efeitos da integração regional e possuem maior necessidade de adequação a esse novo desafio.

O governo subnacional é uma organização formal com limites territoriais, população e funções definidos. $\mathrm{Na}$ perspectiva adotada pela referida pesquisa, o Estado é entendido como um conjunto de elementos interdependentes, que integram e fazem a alocação de valores na sociedade. Ao mesmo tempo, é integrante de um sistema mais amplo, o nacional, que o limita e influencia nessa função.

Em princípio, a esfera subnacional é um meio para que o sistema alcance suas finalidades e as defina. Seu objetivo é prestar serviços à população a qual se refere, mas também incorpora tarefas que beneficiam o sistema federal e geram produtos políticos.

No caso da política externa e da integração regional, agrega-se a esse cenário um outro elemento desconsiderado até o momento: os governos subnacionais não são considerados pelo direito internacional público como atores válidos desse sistema. Portanto, sua participação deve ser realizada por meio das instituições federais competentes.

Essa relação entre a esfera subnacional e a federal, no tocante às questões da integração regional e da política externa, em geral, está em construção no Brasil, embora os Estados atuem nessa área e, principalmente, sofram influências e pressões do cenário externo. Será analisada, neste artigo, a forma como o Estado de São Paulo está se inserindo neste contexto internacional marcado pelos fenômenos da globalização e da regionalização, a partir de sua relação com o governo federal e os órgãos internacionais.

\section{INFLUÊNCIAS DAS INSTITUIÇÕES INTERNACIONAIS NO ESTADO DE SÃO PAULO ${ }^{2}$}

Com o fim da guerra fria, no final dos anos 80 , as análises das relações internacionais de certa forma entraram em "crise", pois tiveram que adequar seus pressupostos a uma nova realidade ou ordenamento que ainda hoje não está bem definido. O único consenso a que se chegou é o da importância crescente da esfera econômica na determinação dos relacionamentos entre os Estados, fenômeno esse traduzido muitas vezes no conceito de globalização. Como afirma Fonseca Jr. (1994:70), "se existe alguma unanimidade entre os analistas do sistema internacional, é a de que vivemos um momento de transição. $\mathrm{O}$ fim dramático e repentino da guerra fria obriga a repensar a ordem política, os mecanismos de segurança e de solução de controvérsias, o papel dos organismos multilaterais".

Esse panorama difuso permitiu que a globalização se tornasse um importante elemento explicativo do que ocorre mundialmente, considerando-se especialmente seus efeitos sobre os Estados e na redefinição da ordenação tradicional do sistema internacional, ao fortalecer o papel das empresas multinacionais como atores relevantes em detrimento dos governos, que estariam perdendo o controle sobre a circulação de capitais e investimentos.

Desta forma, seria vivenciado o surgimento de uma nova ordem mundial baseada não mais na força e no poder das nações, mas sim nas interações comerciais e financeiras que condicionariam os próprios interesses dos países e suas estratégias de ação. Para além disso, estar-se-ia vivenciando a ascensão das localidades (cidades, regiões e estados) como centros de decisão na promoção do bem-estar social, de inserção internacional e do desenvolvimento (Castells, 1999).

Esse novo status tem reflexos diretos na relação dessas localidades com o contexto nacional e o externo. As localidades ganham importância na definição dos rumos da política externa dos países, porque a implementação das decisões tende a ser cada vez mais descentralizada, assim como seus efeitos. Pode-se analisar esta nova situação dentro de uma lógica como a do modelo de Putnam (1993) dos Two-Level Games (Jogos de Dois Níveis), em 
que toda atuação de um governo nacional no âmbito internacional envolve dois processos de negociação: um voltado para os atores externos e outro para os domésticos.

O pressuposto dessa teoria é que os acordos e compromissos assumidos internacionalmente necessitam de apoio interno para serem efetivamente implantados. Nesse sentido, os governos são obrigados a negociar no plano nacional para criar uma base de sustentação que permita essa implementação. As relações externas de um país tornamse muito mais dinâmicas e complexas porque supõem um diálogo constante em duas frentes e a acomodação permanente dos interesses em cada uma delas. Origina-se com isso uma relação de duplo sentido: as estratégias de uma esfera devem levar em conta as da outra.

Verifica-se esta simbiose entre o governo brasileiro e o Estado de São Paulo quando se consideram as relações com alguns organismos internacionais: o Fundo Monetário Internacional (FMI); o Banco Mundial (Bird); e o Banco Interamericano de Desenvolvimento (BID).

\section{Fundo Monetário Internacional}

O FMI negocia sempre diretamente com o governo federal brasileiro, no entanto, verifica-se que os resultados dessas negociações tiveram impactos diretos sobre os governos estaduais, especialmente o de São Paulo.

A relação do Brasil com o FMI passa necessariamente por dois momentos: o de resistência diante das pressões internacionais sobre o governo federal que necessita recorrer ao FMI e deve se adequar às imposições desse órgão; e o de negociação e barganha com as demais esferas governamentais nacionais e os diferentes grupos de interesse que deverão participar da implementação dessas decisões e sofrerão diretamente os seus impactos.

O Brasil entrou no FMI em 14 de julho de 1955, embora somente em 1958 tenha recebido o primeiro financiamento dessa instituição. Era um financiamento a curto prazo (de 12 a 18 meses) para países com problemas temporários na balança de pagamentos. Durante os anos $60 \mathrm{e}$ 70, os empréstimos do Brasil junto ao FMI foram feitos sem a necessidade de programas de ajuste, e foram raras as vezes que o Brasil precisou de programas mais rígidos que sugeriam alterações na sua política interna.

Essa situação alterou-se a partir da década de 80, quando o Brasil enfrentou uma forte crise, com aumento do endividamento externo, desvalorização da moeda em um contexto externo de altas taxas de juros e encarecimento do dólar, recessão em nível global e inflação crescente.
Os países da América Latina foram forçados a iniciar um processo de reestruturação de suas economias, para fazer frente aos serviços da dívida e à nova realidade do mercado internacional. Além dos problemas econômicos, essa crise acarretou desgastes sociais, principalmente o agravamento da pobreza e o aumento do desemprego.

A solução apresentada pelo sistema internacional a países como o Brasil, ${ }^{3}$ que haviam aplicado uma estratégia desenvolvimentista alternativa, para sua adequação à nova realidade econômica mundial era a aplicação de um "pacote de políticas econômicas" proposto pelas instituições multilaterais localizadas em Washington, ${ }^{4}$ como é o caso do FMI, do Banco Mundial e do BID. Essas políticas enfatizavam a liberação dos fluxos comerciais, a atração de investimentos externos, a desregulamentação da economia, a redução do papel do Estado, a renegociação da dívida externa no âmbito do Plano Brady e a supervisão, por parte dessas instituições internacionais, da aplicação dessas políticas econômicas.

Essa crise na economia internacional fez com que muitos países em desenvolvimento, e entre eles o Brasil, apresentassem o risco de inadimplência e, conseqüentemente, procurassem, com mais freqüência, empréstimos do FMI.

Embora o Brasil tenha recorrido e negociado com o FMI ao longo dos anos 80 , foi somente no início da década seguinte, durante a presidência de Fernando Collor de Mello, que o governo internalizou de fato na sua política econômica as recomendações dessa instituição, elaborando um plano econômico conforme o modelo do FMI, que mesclava política monetária, liberalização do comércio e taxa de câmbio flutuante. No entanto, tanto no período Collor como no de seu sucessor (Itamar Franco), o Brasil não conseguiu cumprir com as determinações do Fundo, levando a renegociações constantes e suspensão dos empréstimos.

Apenas no governo Fernando Henrique Cardoso o País iniciou um processo de mudanças aprovado pelo FMI e, conseqüentemente, as relações Brasil-FMI tornam-se mais estreitas e os investimentos maiores. Embora o FMI não proporcione financiamentos para os governos subnacionais, pois todos os seus empréstimos se direcionam para a União, os impactos dos acordos estendem-se aos Estados e municípios.

O que importa ao FMI é o ajuste fiscal que se concentra no âmbito federal. Aos Estados e municípios coube contribuir com esse ajuste, reestruturando equilibradamente seus débitos com o governo federal e colaborando com as leis da reforma administrativa. Com isso, os Estados foram, e ainda são, influenciados indiretamente 
pelas políticas adotadas pela União de acordo com as orientações do FMI.

O Estado de São Paulo, devido à sua importância econômica, sentiu de forma intensa os efeitos dessa reestruturação política federal. Na retrospectiva apresentada pelo governo Mario Covas, publicada na Internet, a maior tarefa desse Estado foi sanear o sistema financeiro e reorganizar a administração. Para isso foi privilegiada uma política de acabar com o déficit público, realizar privatizações e fazer um saneamento das empresas estatais. Em última análise, ocorreu uma reprodução, por parte do poder público estadual, das ações do governo federal no sentido de acatar as sugestões de política econômica formuladas pelo FMI.

\section{Banco Mundial}

O Banco Mundial financia programas no Brasil desde 1949, tendo aprovado 240 projetos até o final de 2000, com um custo total de US\$ 23 bilhões para o País. Devese ressaltar, no entanto, que a partir da década de 80 , o Banco passou a enfatizar a questão social, destinando para isso cerca de $19 \%$ dos seus empréstimos.

Esse novo direcionamento na estratégia do Bird significou sobretudo mudanças nas diretrizes do Banco, num contexto de forte crise nos países em desenvolvimento. Nessa conjuntura, o Brasil também modificou seu posicionamento perante os órgãos financeiros internacionais, passando a participar de forma mais intensa nos programas de estabilização propostos por essas instituições. Conseqüentemente, esses programas passaram a influenciar a política interna e a própria legislação brasileira.

Contudo, da mesma forma como ocorreu com o FMI, foi somente a partir dos anos 90 e, especialmente, após 1995, que esse alinhamento em relação às determinações dos órgãos internacionais foi incorporado no Brasil a um programa interno de reforma da política econômica (por meio de programas de privatizações, maior abertura econômica, desregulamentação do mercado financeiro, redução dos desequilíbrios dos gastos do setor público).

A partir desse momento, a relação Brasil-Banco Mundial tornou-se mais estreita, sendo que muitas diretrizes dessa instituição internacional passaram a influenciar áreas de atuação dos governos federal e estadual. Essa influência concentrou-se nas políticas sociais, com destaque para a questão educacional.

Do ponto de vista do Banco Mundial, a educação é extremamente importante para o desenvolvimento de um país, sendo uma das principais armas para garantir eficiência no ajuste estrutural e no combate à pobreza. $\mathrm{O}$ Brasil, em virtude da ligação com o Bird e da necessidade de promover ajustes na organização do Estado, vem adotando uma série de medidas para o desenvolvimento da educação brasileira baseando-se nas recomendações do Banco Mundial.

No Brasil, a partir da década de 90, os empréstimos para a educação aumentaram significativamente. Entre 1987 e 1990 eram de 2\%, enquanto de 1991 até 1994 passaram para 29\% (Tommasi, 1996). Em 1998, um novo programa baseado nas novas concepções do Banco foi aprovado pela primeira vez no Brasil e recebeu o nome de Fundescola, que na visão do Bird é um de seus projetos mais importantes.

Todas as ações educacionais do Banco Mundial no Brasil, em 1998, alcançaram o montante de US\$1,13 bilhão, com o seguinte destino: Educação Básica para o Nordeste II; Educação Básica para o Nordeste III; Fundescola I; e projetos diretamente ligados com os Estados de São Paulo, Paraná, Minas Gerais e mais o Terceiro Projeto de Tecnologia e Ciência.

Em São Paulo, esse projeto educacional (elaborado em 1999) seguiu as orientações do Bird, prevendo realização de estudos, apresentação dos resultados em conferências e abrangendo as questões da infra-estrutura. O projeto recebeu um investimento inicial do Banco Mundial de US\$ 245 milhões (o total investido pelo País é de US\$ 605 milhões).

A saúde é outra área para a qual o Banco Mundial concedeu investimentos. Em 1998, o Ministério da Saúde brasileiro recebeu US\$ 165 milhões para continuar seu projeto de combate à Aids e doenças sexualmente transmissíveis. É importante destacar que esse projeto transfere as responsabilidades da União para os Estados e municípios, tendo impacto direto sobre seus programas de saúde.

Um outro setor que recebeu atenção do Bird foi o agrário. Em 1997, o Banco concedeu um empréstimo de US\$ 60 milhões para o governo brasileiro, visando a promoção de melhorias nas pesquisas nessa área. No biênio 1998-99, continuaram a existir projetos para a agricultura, mas esses foram mais específicos, destinando-se a determinadas áreas do País, entre elas o Estado de São Paulo.

A relação mais direta entre o Banco Mundial e o Estado de São Paulo, no entanto, se dá por meio da Corporação Financeira Internacional (CFI), uma das instituições financiadoras do Bird, cuja função é criar condições para os países em desenvolvimento expandirem os investimentos do setor privado. Seu foco de atuação é a regulamentação das leis para uma melhor eficiência do setor priva- 
do, a construção da infra-estrutura necessária para a inserção do País no mercado internacional e a promoção do desenvolvimento do setor bancário. O Brasil, participa da CFI desde 1958, tendo recebido 140 financiamentos, o que significou um investimento total de US\$ 4,3 bilhões, em projetos que tiveram um custo total para o Brasil de US\$ 15 bilhões.

Como em São Paulo o setor privado é bastante forte, este Estado recebeu amplo investimento da CFI, sendo mais de US\$ 3,5 bilhões, nos últimos cinco anos (de 1995 a 2000), distribuídos pelos diferentes setores da economia. A educação recebeu aproximadamente $17,5 \%$ desse valor (US\$ 615 milhões), seguida pelo setor de infra-estrutura, com quase $15 \%$ (US\$ 523 milhões). Os setores de telecomunicações, financeiro e petroquímico captaram cerca de $9 \%$ cada (US\$ 310 milhões, US\$ 330 milhões e US\$ 315 milhões, respectivamente). A área de saúde recebeu US\$ 300 milhões $(8,5 \%)$, e os demais setores ficaram, cada um, com $5 \%$ ou menos do total desses investimentos.

Os dados analisados e aqui apresentados demonstram que, a partir de 1996, os empréstimos aumentaram, com investimentos direcionados para as indústrias em geral e empresas dos setores de agroindústria e de infra-estrutura. Em 1997, a CFI começou a investir também no sistema financeiro e na educação do Estado de São Paulo.

O governo de São Paulo, nesse contexto, viu-se forçado a promover algumas mudanças, no sentido de construir uma nova estratégia política que possibilitasse sua melhor inserção internacional e a atração de investimentos. No caso específico do Banco Mundial, essa consideração torna-se mais relevante quando se pondera que o Bird realiza projetos diretamente para o Estado de São Paulo e que mesmo aqueles destinados à União acabaram promovendo transformações neste Estado.

\section{Banco Interamericano de Desenvolvimento}

O BID foi criado em dezembro de 1959 como um banco regional de desenvolvimento, complementar às instituições de Bretton Woods. Desde o início, a questão da integração regional ocupou um lugar de destaque na estratégia dessa instituição, cujos objetivos são a promoção do investimento de capital público e privado na região, a proteção da economia dos países-membros, o estímulo para a atração de capitais privados que possam contribuir com o desenvolvimento da região e a assistência técnica para elaboração, financiamento e execução de programas de desenvolvimento.
Ao longo de sua história podem ser identificados três direcionamentos nas políticas dessa instituição: durante a década de 60, o BID privilegiou as atividades na área de educação (especialmente para a população rural), de serviços básicos de saúde, de desenvolvimento de ciência e tecnologia, de fortalecimento e criação de instituições públicas e privadas, de melhorias nas políticas econômicas e de desenvolvimento industrial e da infra-estrutura básica; nos anos 70 e 80 , sua atenção voltou-se para as questões de infra-estrutura; no final dos anos 80 , esta posição alterou-se, marcando a década seguinte por uma orientação direcionada para a reestruturação das economias latino-americanas.

Deve-se lembrar que o início da década de 90 foi marcado por um processo de abertura econômica dos países da América Latina em relação ao mercado internacional. Esse processo teve apoio norte-americano e das instituições financeiras internacionais, que consideraram essa estratégia a melhor maneira de contornar a crise dos anos 80 . Neste contexto, o apoio do BID tornou-se uma alternativa aos países da região para impulsionar o desenvolvimento dentro dessa nova política de reestruturação econômica.

Os financiamentos do BID para o Brasil na década de 90 voltaram-se, na sua maioria, para os projetos de infraestrutura. Isto ocorreu também em relação ao Estado de São Paulo, pois, segundo a avaliação do Banco, o rápido crescimento econômico desse Estado não foi acompanhado pelo desenvolvimento de uma infra-estrutura adequada, gerando a necessidade de fortes investimentos nesse setor, como medida necessária para garantir seu crescimento contínuo.

Nesse sentido, o BID financiou no Estado de São Paulo os projetos de despoluição do rio Tietê, de modernização da Rodovia Fernão Dias que liga a capital paulista à capital mineira, de modernização do sistema de trens metropolitanos, das estradas que ligam São Paulo a Santa Catarina, do sistema de drenagem, das favelas, entre outros.

Alguns investimentos do BID para o governo federal tiveram repercussão direta nos governos subnacionais, como o programa de ajuste estatal (dentro da lógica de promover a reforma do Estado) que foi um projeto federal, mas continha linhas específicas para promoção de reformas estaduais, como o programa de administração fiscal para os Estados. Ou então, projetos de infra-estrutura nacional como o Gasoduto Bolívia-Brasil, que representou para São Paulo a possibilidade de uma alternativa energética para suas indústrias. Além disso, o BID deu assistência técnica ao projeto hidroviário Paraná-Paraguai, 
que, embora não tenha beneficiado diretamente o Estado de São Paulo, teve repercussões positivas sobre o projeto da hidrovia Tietê-Paraná.

O BID está preocupado com a modernização do Estado de São Paulo, seja na sua infra-estrutura física e social, seja na reforma do aparelho estatal, pois estes seriam os aspectos que permitiriam a esse Estado maior poder competitivo no cenário internacional.

\section{O ESTADO DE SÃO PAULO NO MERCOSUL ${ }^{5}$}

Verificou-se, na pesquisa, a influência das instituições internacionais na atual política administrativa do Estado de São Paulo. Essa relação tem sido basicamente reativa por parte do governo desse Estado, que procurou adequar-se às normas e às determinações desses organismos para obter os financiamentos necessários para a promoção de seus programas sociais, de desenvolvimento e infra-estrutura.

No entanto, supunha-se, no início da pesquisa, que essa postura poderia ser diferente em alguns casos, com o governo estadual tendo uma ação mais propositiva a fim de aumentar seus benefícios. O pressuposto era de que, no caso específico do Mercosul, o governo do Estado de São Paulo poderia ter essa postura positiva devido ao grande intercâmbio comercial com os demais países do bloco.

A pauta de exportações paulistas é bastante diversificada, destacando-se a participação significativa dos setores dinâmicos da indústria como o setor automotivo, o de máquinas e equipamentos e o setor químico. As exportações dos produtos da indústria química e conexas representaram 7,79\%, em 1996, e 7,71\%, em 1997, das exportações do Estado; as de máquinas e aparelhos, material elétrico, etc., corresponderam a $23,05 \%$ e $22,75 \%$ e as de material de transporte equivaleram a $15,58 \%$ e $20,70 \%$.

Nota-se que os produtos mais sofisticados, com maior utilização de capital, apresentam um grau de exportação para o Mercosul de mais de $40 \%$, enquanto os segmentos mais tradicionais da indústria, como alimentos e bebidas, calçados e metalurgia básica, correspondem a mais de $80 \%$ de vendas para outros países. Assim, os produtos com maior utilização de capital encontram melhor mercado nos países do Mercosul, que é o principal destino das exportações do Estado. Em 1998, a soma do valor das exportações do Estado para os países do Bloco ficou em US\$ 4.734 milhões, superando em US\$ 913 milhões as exportações para os Estados Unidos, sendo este país o principal destino das exportações do Brasil.
A relevância do Estado de São Paulo neste comércio com o Mercosul é verificada quando se considera a importância dos produtos industrializados na pauta de exportações brasileiras, que representam cerca de $94 \%$ para o Mercosul. Tendo em vista a característica industrial paulista, que concentra grande parte do parque industrial do País, imagina-se que haveria uma tendência por parte de seu governo de buscar maximizar sua participação nesse mercado regional.

Contrariamente ao que se imaginava - em virtude das condições estruturais do Estado de São Paulo e do contexto internacional favorável à emergência das unidades subnacionais $-\mathrm{a}$ análise das atas das reuniões do Conselho Mercado Comum (CMC) e do Grupo Mercado Comum (GMC), juntamente com notícias de jornais, não permite identificar o Estado de São Paulo como ator subnacional ativo no contexto do Mercosul, ou do governo estadual enquanto um possível interlocutor dos interesses paulistas.

Da mesma forma, no que se refere aos conflitos comerciais no Mercosul, o governo de São Paulo não apresentou um posicionamento de intervenção ou de acompanhamento sistemático das negociações, mesmo quando os envolvidos são setores importantes para a economia paulista, como é o caso do setor automotivo e do açúcar. As negociações geralmente têm sido realizadas entre os representantes empresariais e o governo federal.

A perspectiva era identificar mudanças na formulação da agenda política ou de adaptação organizacional do governo de São Paulo. Verificou-se que, pelo menos nos últimos dez anos, a administração estadual paulista não desenvolveu atividades significativas com relação ao Mercosul ou à integração latino-americana. Para um importante membro do governo paulista, o Mercosul é visto como uma experiência comercial que tem seu ponto central na ação das empresas privadas e o governo intervém para resolver eventuais impasses (Fontana, 2000).

A partir destas considerações, constatou-se que o governo do Estado de São Paulo reúne as condições necessárias para despontar como um ator importante no contexto regional e internacional, mas até o momento isso apenas tem se traduzido em potencial. A análise empírica aponta em sentido contrário. É essa situação paradoxal que esta pesquisa pretende esclarecer, possibilitando compreender melhor a dinâmica da ascensão dos governos subnacionais no âmbito dos processos de integração regional e também no sistema internacional, além da configuração de cenários que tornam isso possível. 


\section{LIMITAÇÕES DE UM ESTADO SUBNACIONAL NAS RELAÇÕES INTERNACIONAIS}

São vários os fatores que poderiam explicar o baixo envolvimento do governo do Estado de São Paulo no Mercosul e a sua postura mais reativa em relação às pressões internacionais. Neste último caso, os problemas econômicos e sociais desse Estado fragilizam sua capacidade de responder ou formular estratégias de forma autônoma a esses desafios. Ao mesmo tempo, as fontes para a obtenção dos recursos condicionam suas alternativas.

Quando o financiamento é repassado pelo governo federal, a negociação tende a se direcionar para a adequação às políticas de reforma e reajuste implementadas nessa esfera e, na sua maioria, em conformidade com as recomendações das instituições internacionais. Nos casos em que o financiamento é obtido diretamente junto aos organismos internacionais, essas adequações estão incorporadas nos próprios termos das negociações.

No que se refere à integração regional, pode-se dizer que o problema central encontra-se na forma como os governos subnacionais relacionam-se com o governo federal no tocante à formulação da política externa brasileira. Tradicionalmente, esta concentra-se no Ministério das Relações Exteriores (MRE), que possui pouca interlocução com os governos estaduais, embora esteja buscando alterar essa situação com a criação da Assessoria e Relações Federativas, instalando escritórios em alguns Estados, entre eles no de São Paulo.

Essa falta de interlocução, no entanto, não afetou o desempenho dos setores produtivos paulistas que apresentaram um bom aproveitamento das oportunidades de negócio no Mercosul. O governo de São Paulo não foi pressionado a intervir de forma mais direta nas negociações relativas à integração, não sentindo necessidade de criar mecanismos e canais de participação apropriados na estrutura institucional desse processo.

Até o momento, o governo brasileiro não reconheceu os Estados como atores internacionais, fato este que tem limitado a sua intervenção no Mercosul, com exceção dos casos de ação judicial nos momentos de conflito, mas, ainda assim, a intervenção estadual ocorre de forma marginal.

O Estado subnacional não pode ser tratado como um ator interno apenas porque possui capacidade decisória institucionalizada sob o território a que se refere. Na verdade, possui para a esfera subnacional, em princípio, as mesmas atribuições de um Estado federal. Ou seja, aco- moda os diferentes interesses e, a partir deles, busca definir seus objetivos e negociar com os demais atores.

As noções de vulnerabilidade e sensibilidade provenientes da teoria da interdependência (Keohane e Nye, 1989) ajudam a traçar a situação de um governo subnacional. Sua ascensão é um fenômeno recente e sua capacidade para lidar com as questões externas está em processo de desenvolvimento.

Os governos subnacionais são muito vulneráveis nos processos de integração regional porque não possuem poder decisório direto para lidar com seus efeitos. Quando um Estado é prejudicado por uma política adotada no Mercosul, por exemplo, tem que se reportar à estrutura do governo federal para conseguir alguma compensação, ou adaptar-se para minimizar suas perdas, o que nem sempre é viável. Uma forma de enfrentar essa tendência é a criação de mecanismos decisórios ou estruturas capazes de representar os interesses subnacionais e influir tanto no interior do Estado nacional quanto no âmbito da integração regional.

Um exemplo disso seria a última reforma constitucional argentina, que permitiu às províncias negociarem acordos internacionais, desde que não entrem em contradição com os compromissos assumidos pelo Estado nacional, ou então como no caso do Estado de Otawa, Canadá, que tem ascendido enquanto ator internacional, principalmente devido à sua importância econômica, comercial e tecnológica para o país.

Outra opção é a criação, dentro da estrutura da integração, de espaços formais de participação dos Estados, e mais especificamente de seus representantes governamentais, tal como ocorre na União Européia com o Comitê das Regiões. Sendo o mais recente órgão criado no âmbito da experiência européia, tornou-se necessário quando a integração alcançou o estágio de desenvolvimento de uma união econômica. Isto não implica afirmar que, numa integração intergovernamental, como é o caso do Mercosul, os interesses subnacionais não são ainda relevantes para o seu avanço. Porém, pode-se direcionar a análise no sentido inverso, de saber se estes interesses estão se tornando relevantes a ponto de indicar se o processo caminha para a criação de instituições supranacionais.

Este princípio supõe que as diferentes esferas de poder, e entre elas a estrutura regional, possuem capacidade de aplicar suas decisões. Sua aplicação é válida na Europa porque há supranacionalidade, o que não ocorre no Mercosul. A lógica de negociação, neste caso, está 
mais próxima da Teoria dos Two Level Games, em que os Estados negociam entre si e com os seus respectivos atores internos. Sendo assim, o Estado de São Paulo não necessita participar diretamente das negociações relativas ao Mercosul porque sua intervenção se dá no plano doméstico. Porém, esta é uma situação que aumenta sua vulnerabilidade.

No mesmo sentido, alguns itens levantados por Keohane e Nye (1981) a respeito da ascensão dos atores transnacionais também podem ser aplicados aos governos subnacionais como forma de análise empírica: relacionamento com as estruturas políticas nacionais, regionais e transnacionais; alterações na percepção e nas atitudes dos formuladores governamentais; possíveis relações de dependência ou interdependência criadas; modificações organizacionais no sentido de criar novas estruturas ou formas de influência; e ascensão de setores no âmbito subnacional com capacidade de desenvolver alternativas de inserção próprias.

À medida que a integração se expande, com o avanço das negociações, o governo subnacional busca alternativas para influenciar o processo, seja formalmente, através de sua adaptação organizacional à nova situação e da utilização dos mecanismos decisórios institucionalizados no nível nacional, seja informalmente, por meio da criação de canais de influência em setores governamentais ou privados diretamente envolvidos com o processo de integração.

Esta questão levanta um outro problema: os interesses relativos ao processo de integração não são encaminhados aos governos estaduais, mas diretamente aos órgãos federais que participam das negociações do Mercosul e possuem capacidade real de influenciar as decisões. Aos governos subnacionais podem ser encaminhadas as demandas daqueles negativamente afetados, que buscam na esfera subnacional as compensações que não receberam do governo federal.

Enquanto os impactos negativos do Mercosul forem difusos e localizados, o governo do Estado de São Paulo tende a manter a sua atual postura de não participar de maneira mais ativa no processo de integração. Contudo, a nova lógica internacional, marcada pela ascensão das localidades, exigirá dos governos estaduais estratégias específicas e bem definidas de inserção internacional.

\section{NOTAS}

1. O termo spillover não possui uma tradução teórica específica e, por isso, será sempre usado em inglês; seu significado está ligado à idéia de "derramamento", de algo que se inicia num determinado ponto e "transborda".

2. Esta parte do texto contou com a colaboração de Maíra Junqueira Neves.

3. A política de substituição de importações gerou no Brasil, durante a década de 70, o chamado "milagre econômico", baseado na concepção cepalina de que o protecionismo promoveria o desenvolvimento industrial e tornaria o país autônomo em relação ao mercado internacional. Apesar da promoção efetiva do desenvolvimento do parque industrial brasileiro, de forma geral este não acompanhou os níveis de competitividade existentes no mercado mundial, representando hoje um sinal da sua fragilidade diante da competição externa e, em certos casos, um acomodamento resultante das garantias e auxílios do protecionismo.

4. Daí ter-se chamado este conjunto de políticas de "Consenso de Washington".

5. Esta parte do texto contou com a colaboração de Carolina Gil Santos e Ricardo Glöe Mendes.

\section{REFERÊNCIAS BIBLIOGRÁFICAS}

CASTELLS, M. A Era da Informação: economia, sociedade e cultura. Volume 3: Fim de Milênio. São Paulo, Paz e Terra, 1999.

FONSECA Jr., G. "Notas sobre os processos de integração e a Ordem Internacional". Mercosul: desafios a vencer. São Paulo, Conselho Brasileiro de Relações Internacionais (CBRI), 1994, p.69-78.

FONTANA, J.Z. Assessor Especial da Secretaria de Ciência Tecnologia e Desenvolvimento Econômico do Governo do Estado de São Paulo. São Paulo, entrevista realizada em 19/10/2000.

FUNDAP/CEDEC/PUC. Gestão Pública Estratégica de Governos Subnacionais Frente aos Processos de Inserção Internacional e Integração Latino-Americana. Primeiro relatório científico. São Paulo, mar. 2000.

KEOHANE, R.O. e NYE, J.S. "Transnational relations and world politics: an introducion". In: KEOHANE, R.O. e NYE, J.S. Transnational relations and world politics. Harvard, Harvard University Press, 1981.

. Power and interdependence. Boston, Scott, Foresman and Company, 1989.

PUTNAM, R.D. "Diplomacy and domestic politics. The logic of TwoLevel Games”. In: EVANS, P.B.; JACOBSON, H.K. e PUTNAM, R.D. Double-edged diplomacy: international bargaining and domestic politics. California, University of California Press, 1993.

TOMMASI, L. de. "Financiamentos do Banco Mundial no setor educacional brasileiro: os projetos em fase de implementação". In: TOMMASI, L. de; WARDE, M.J. e HADDAD, S. (orgs.). O Banco Mundial e as políticas educacionais. São Paulo, Cortez Editora, 1996.

Karina L. Pasquariello Mariano: Cientista politica, Pesquisadora do Cedec (p_mariano@uol.com.br). 